\title{
Thaon - Église Saint-Pierre
}

\section{François Delahaye et Vanessa Brunet}

URL : http://journals.openedition.org/adlfi/7351

ISSN : 2114-0502

Éditeur

Ministère de la culture

Référence électronique

François Delahaye et Vanessa Brunet, «Thaon - Église Saint-Pierre », ADLFI. Archéologie de la France Informations [En ligne], Basse-Normandie, mis en ligne le 01 mars 2007, consulté le 03 mai 2019. URL http://journals.openedition.org/adlfi/7351

Ce document a été généré automatiquement le 3 mai 2019.

(c) Ministère de la Culture et de la Communication, CNRS 


\title{
Thaon - Église Saint-Pierre
}

\author{
François Delahaye et Vanessa Brunet
}

Date de l'opération : 2007 (FP)

Inventeur(s) : Delahaye François (INRAP) ; Brunet Vanessa (INRAP)

1 La campagne de fouille 2007 qui s'inscrit dans un nouveau programme pluriannuel pour les années 2007-2009, a été marquée par la forte remontée de la nappe phréatique engendrée par les intempéries du printemps et accentuée par les précipitations abondantes de la seconde moitié du mois de juillet. L'inondation des zones de fouille à l'intérieur de l'église n'a pas permis de poursuivre les recherches dans le chœur, la travée sous clocher et les deux travées orientales de la nef.

2 L'étude des premières travées de la nef a permis de mettre au jour un nouveau mur, orienté nord-sud, partiellement recouvert par plusieurs inhumations. Sa mise en œuvre constituée de blocs calcaires assisés liés par un mortier compact blanchâtre, permet de le rapprocher des maçonneries attribuées à l'occupation antique du site qui se développe au cours des $\mathrm{II}^{\mathrm{e}} \mathrm{s}$. et $\mathrm{III}^{\mathrm{e}} \mathrm{s}$. Ce nouveau tronçon dont le dégagement sera poursuivi lors de la prochaine campagne, permet de compléter le plan de cet établissement gallo-romain. Dans la troisième travée, ce sont les traces d'un second moule à cloche qui ont pu être mises en évidence. Ce moule se différencie de celui mis au jour dans la première travée l'année dernière par ses dimensions plus modestes, par sa localisation dans l'axe médian de la nef et par son niveau d'apparition relativement haut, ce dernier conduisant à penser qu'une partie de sa structure initiale pourrait être encore conservée.

3 À l'issue de cette dernière campagne, trois cent dix-sept sépultures ont été identifiées dans l'église Saint-Pierre ou dans ses abords immédiats (Fig. $\mathrm{n}^{\circ} 1$ : Plan général des structures et sépultures mises au jour à l'issue de la campagne 2007). La fouille a porté cette année principalement sur des inhumations en cercueil et sur plusieurs sépultures d'immatures et de périnataux inhumés dans des tombes aménagées avec encadrement en pierres calcaires. La présence en grand nombre de ces sépultures dans ce secteur de l'église est à relever. Elle corrobore les hypothèses développées lors des dernières campagnes concernant la répartition des sépultures selon des critères sociaux et d'âge. 
Dans le cas présent, ces sépultures d'enfants seraient à mettre en relation avec la présence des fonts baptismaux qui sont le plus souvent situés proches du portail occidental.

\section{ANNEXES}

Fig. $\mathrm{n}^{\circ} 1$ : Plan général des structures et sépultures mises au jour à l'issue de la campagne 2007

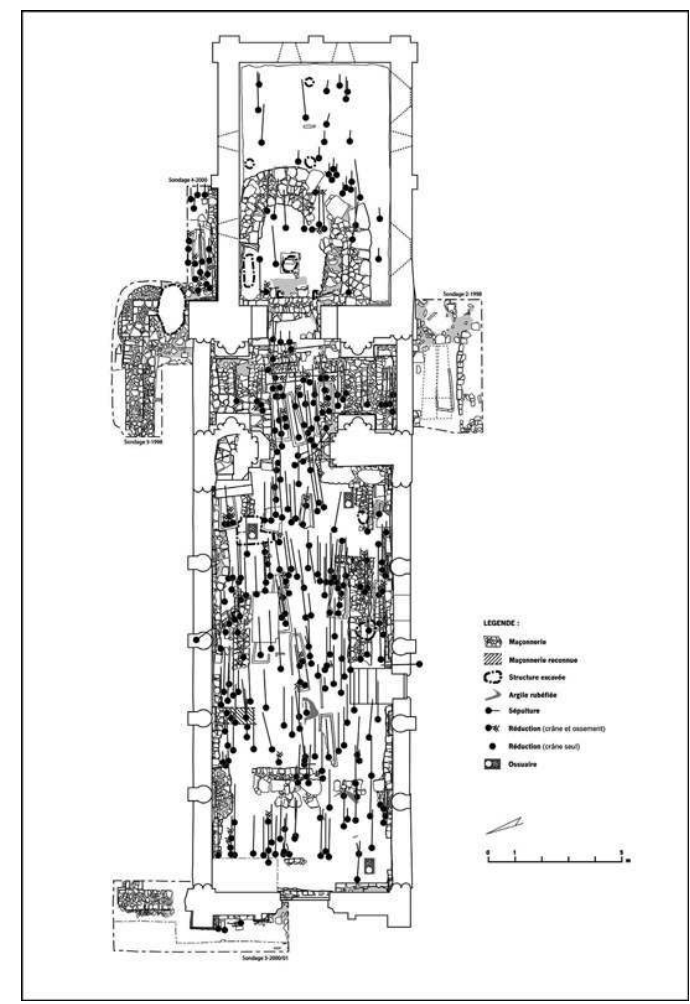

Auteur(s) : Delahaye, François. Crédits : Delahaye, François (2007)

\section{INDEX}

Index chronologique : Empire romain, IIe siècle apr. J.-C., IIIe siècle apr. J.-C., Moyen Âge Index géographique : Basse-Normandie, Calvados (14), Thaon operation Fouille programmée (FP) 
AUTEURS

FRANÇOIS DELAHAYE

INRAP

VANESSA BRUNET

INRAP 